\title{
The Sudbury Basin stress tensor - myth or reality?
}

\author{
FT Suorineni The University of New South Wales, Australia \\ F Malek Vale Canada Ltd., Canada
}

\begin{abstract}
Sudbury Basin is host to many underground mines, most of which are seismically active. Some of these mines, e.g. Creighton Mine, have been in operation for over a century and can be said to be matured. Others, e.g. Glencore Xstrata Nickel Rim South Mine, have just been opened and can be classified as young. Several in situ stress measurements have been performed in these mines over the years. Mine seismicity and rockburst research has been very active in the Sudbury Basin since 1984 following the then Falconbridge Mine disaster. Stress tensor is one of the critical inputs in numerical models for the assessment of excavation performance, support demand and rockbursts and seismicity potential. It is also an important input in closed-form solutions for similar purposes. Over the years, several technical reports have referred to a Sudbury Basin stress tensor. In a recent review study of stress measurements in the Sudbury Basin as a means of validating the so called Sudbury Basin stress tensor, the supposed stress tensor source could be hardly identified. It is important to recognise that in situ stress measurement errors remain significantly high and would be unacceptable in any other branch of engineering (Hoek 1994). To improve confidence in these measurements several carefully measured data are required. For this reason the Sudbury Basin stress tensor if it existed would have had to be updated with the addition of the several stress measurements in the Basin in recent times following its development. Strangely, this is hardly the case. The paper draws the attention of rock engineers to the myth of the Sudbury Basin stress tensor. Based on review of available Vale stress measurement database and interviews of past prominent ground control engineers who have worked in the Basin, including Phil Oliver (pers. comm.) and Dr G Swan (pers. comm.) suggests a plausible, generic, Sudbury Basin stress tensor. The developed stress tensor compares very favourably with what is known from experience in the Basin. The authors give credit to Vale for its continuing effort in stress measurements within the Basin.
\end{abstract}

\section{Introduction}

\subsection{Mining in the Sudbury Basin}

The Sudbury Basin (Figure 1) is an important mining camp. Mines in the Sudbury Basin are in general owned by Vale Canada Ltd. (formerly Inco Ltd.) and Sudbury Integrated Nickel Operations - A Glencore Company (formerly Falconbridge). The Sudbury Basin is an important producer of nickel.

Some of Vale Canada Ltd. mines such as Creighton Mine have been in operation for over a century. Creighton Mine is now approaching 3,000 $\mathrm{m}$ in depth. Several mining methods have been developed in the Sudbury Basin from experience to deal with high stress conditions. The vertical or crater retreat (VRM or VCR) and underhand cut-and-fill mining methods were developed by the then Inco Ltd. to deal with difficult ground conditions - high stress ground conditions. Morrison (1942) developed mining sequences such as the chevron (inverted V) mining to effectively manage rockburst-prone ground conditions. Details of these methods and their application in Vale Ltd. mines are discussed in Oliver et al. (1987).

Research work in the Sudbury Basin underground mines have contributed significantly to the improvement in the understanding and management of rockbursts, ground support efficiency and the development of mining technology. The 'Canadian Rockburst Handbook' (Canadian Mining Industry Research Organization 1995), 'Cable bolts Handbook' and the full waveform seismic monitoring systems currently developed and supplied by the Engineering Seismology Group (ESG) Canada Ltd. in Kingston are key examples of the contributions of research in the Sudbury Basin for the enhancement of mine safety and productivity. 


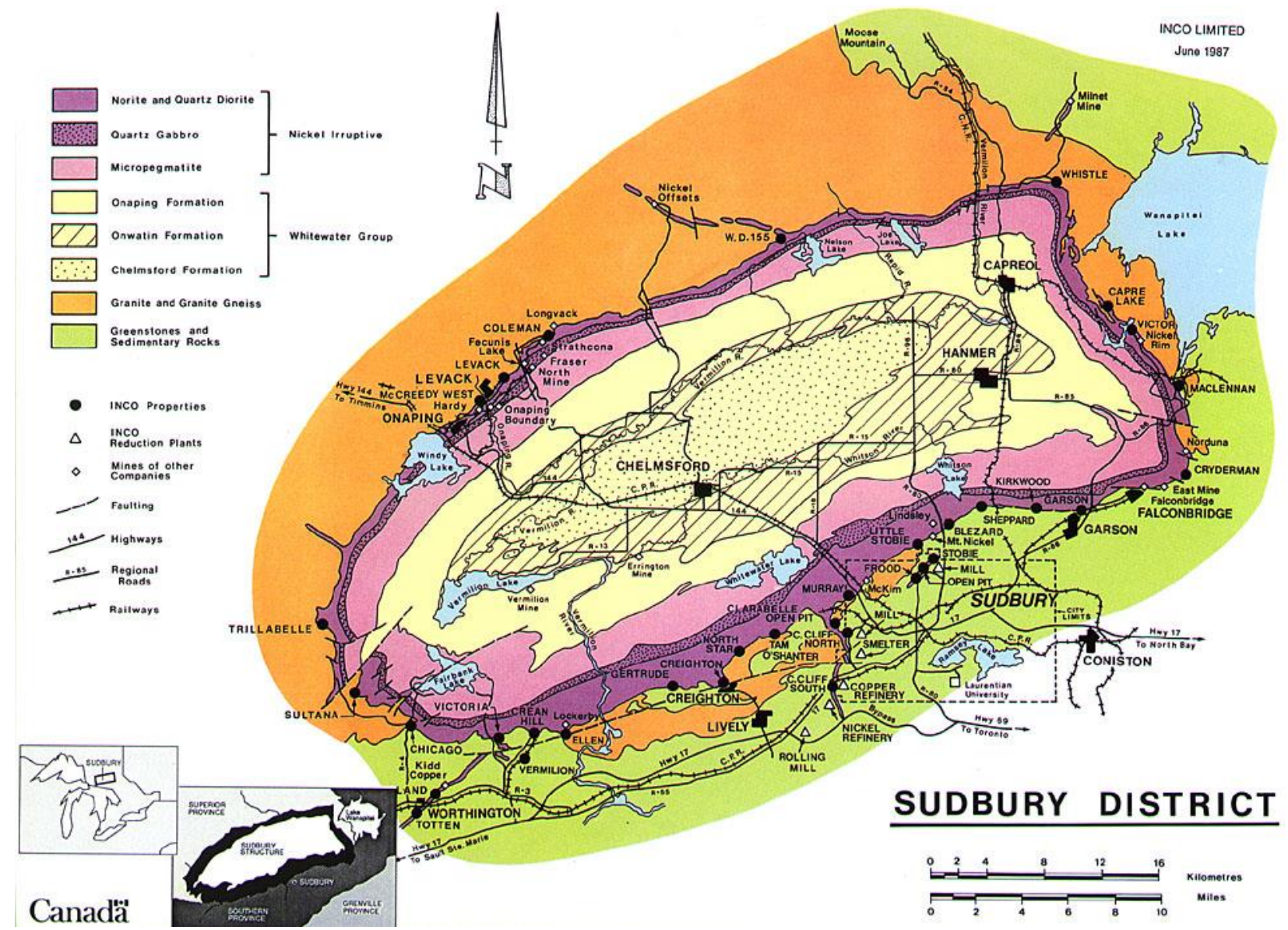

Figure 1 Sudbury Basin showing various underground mines in the Basin (Natural
Resources Canada 2014)

\subsection{Importance of the stress tensor in rock engineering}

Stress tensors and rock mass properties are critical input parameters in rock engineering designs, whether empirical, numerical or analytical. Both the stress state and rock mass properties are quite variable. For this reason probabilistic rather than deterministic approaches are often considered more appropriate in order to account for these variabilities. Data quality and volume are necessary ingredients for database reliabilities in dealing with material property variability.

Data quality and volume assist to minimise errors due to data variability. This is more critical in in situ stress measurement data. Hoek (1994) notes that the errors in in situ stress measurements, when compared to other branches of engineering, are unacceptable. Grabinsky et al. (1997) states that the errors in in situ stress measurement magnitudes are about \pm 15 to $30 \%$ while the errors in orientations vary about \pm 15 to $30^{\circ}$.

Data volume in geotechnical engineering is often limited by cost and accessibility. Clayton (2002) stated that geotechnical site investigation costs are usually less than $1 \%$ of total project costs in civil engineering. It is estimated that in mining projects the amount allocated to geotechnical data collection will even be far less than $1 \%$ of a project cost. It is argued that an increase of site investigation cost from 1 to $5 \%$ on contract value, and even to $25 \%$ does not guarantee elimination of unexpected ground conditions. These arguments are even more important in justifying the number of in situ stress measurement points. The cost for one CSIRO, Australia, Hollow Inclusion (HI) test measurement is about CAD40,000 and yet the quality of the results of the test cannot be guaranteed. These arguments justify occasional updates in in situ stress measurement databases to augment and enhance the reliability of the data. 
The long history of underground mining in the Sudbury Basin and the recognition of the importance of stress in safe and economic mining lead to regular in situ stress measurements in the Vale Sudbury Basin underground mines. A good understanding of in situ stress is the basis for proper management of high stresses in underground mining.

The effort of in situ stress measurements in Canada was pioneered by Herget and supported by Arjang as evidenced in Herget (1987) and Herget and Arjang (1997). In the Canadian Shield most in situ stress measurements and mine stress tensors are referenced to the work of Herget and Arjang. Occasional updates to mine stress measurement data are provided by the Geomechanics Research Centre (GRC) at the Mining Innovation Rehabilitation and Applied Research Corporation (MIRARCO) and the Canada Centre for Mineral and Energy Technology (CANMET), as evidenced in Maloney et al. (2006).

Stress measurement updates are good practice for operating mines that continue to go deeper. Several geological and geotechnical phenomena and observations including rockbursts may trigger in situ stress measurement updates in mines. Villaescusa et al. (2009) carried out such an update for Craig Mine using the acoustic emission (AE) procedure. Updates may take the form of numerical model calibrations based on underground excavations performance observations. Figure 2 provides a flowchart for such a calibration.

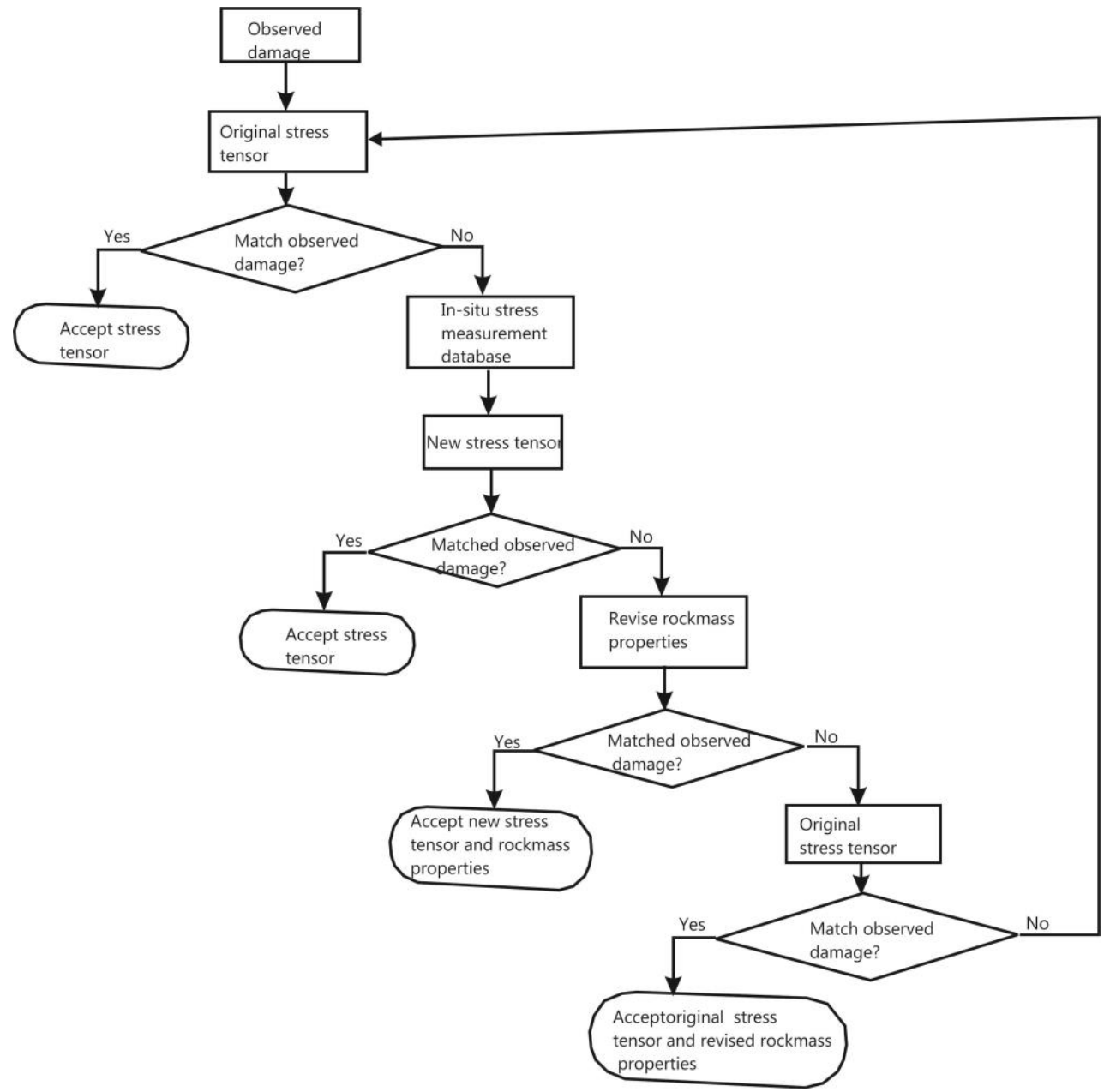

Figure 2 Procedure for mine stress state validation based on numerical model calibration against underground excavations performance observations

For several decades references have been made to a Sudbury Basin stress tensor. The Sudbury Basin stress tensor has formed the basis for most of the mine specific stress tensors in the Basin. The Basin mine specific stress tensors have been derived from the supposed Sudbury Basin stress tensor by calibration against underground observations and or through some additional mine specific in situ stress measurements to validate it. 
Recent studies (Suorineni 2012) prompted an investigation into the source and origin of the Sudbury Basin stress tensor, considering its history and importance in mining in the Sudbury Basin, where high stresses and rockbursting in excavations at depth are common experience. Surprisingly, the source of the Sudbury Basin stress tensor could not be identified and therefore its validity and reliability cannot be confirmed.

This paper traces the source of the Sudbury Basin stress tensor with the objective of providing insight into its validity, and suggests a plausible, defensible Sudbury Basin stress tensor, based on available up to date in situ stress measurements from Vale mines. The authors give credit to Vale for its continuing effort in stress measurements within the Basin to make this study possible.

\section{The Sudbury Basin stress tensor}

\subsection{Background}

It is common practice for technical reports and publications on mines in the Sudbury Basin to refer to a Sudbury Basin stress tensor (Table 1). With the history of stress measurements dating back to late 1970s and early 1980s and continuing one would expect that such a stress tensor would have been updated. This is more so following the various in situ stress measurement updates in the various mines in the Sudbury Basin.

\section{Table 1 The mysterious Sudbury Basin stress tensor}

\begin{tabular}{ccc}
\hline Principal stress & Magnitude $(\mathrm{MPa} / \mathrm{m})$ & Orientation (dip/azimuth) $\left({ }^{\circ}\right)$ \\
\hline$\sigma_{1}$ & $10.862+0.0407 Z^{*}$ & $00 / 090$ \\
$\sigma_{2}$ & $8.690+0.0326 Z$ & $00 / 180$ \\
$\sigma_{3}$ & $0.0292 Z$ & $90 / 000$ \\
\hline
\end{tabular}

${ }^{*} \mathrm{Z}=$ depth below surface in metres

The Sudbury Basin stress tensor is the root for specific mines stress tensors in the Basin. Suorineni (2012) in a recent study sought the evidence for the development of the Sudbury Basin stress tensor. This was prompted by the fact that the reliability of such a stress tensor would have been based on the quality and volume of the database used. The search for the source of the Sudbury Basin stress tensor took the form of a literature survey and interviews of past and current prominent ground control engineers who have worked or are still working in the Sudbury Basin, and experts in in situ stress measurements.

\subsection{Sourcing the Sudbury Basin stress tensor}

The work of Herget and Arjang in the Canadian Shield was reviewed. The Canadian Shield in situ stress measurement database as presented in Maloney et al. (2006) was evaluated.

The author and former co-workers at the GRC conducted several studies on mines in the Sudbury Basin including numerical modelling (Suorineni 2012; Henning and Suorineni 2001), rockburst studies (Vasak and Suorineni 2010; Vasak et al. 2004, 2006), and in situ stress measurements (Maloney and Suorineni 2006). The author has also co-authored various papers with current (Malek et al. 2005, 2008, 2009) and past (Suorineni et al. 2011; Suorineni \& Thibodeau 2013) ground control engineers and management in the Sudbury Basin mines. The authors are thus familiar with the stress tensors in use in mines in the Sudbury Basin and the implications for mine safety and productivity.

Based on the discussions with past and current ground control engineers in the Sudbury basin it was concluded that the source of the Sudbury Basin stress tensor is more of a myth than reality. One renowned ground control engineer in the Sudbury Basin with excellent knowledge both in theory and practice is Phil Oliver. Other pioneers in this area include C Graham, G Swan and D Morrison. Terry Wiles has also been involved in stress analysis and numerical modelling in the Sudbury Basin as far back as the late 1980s. Oliver et al. (1987) provides one of the first attempts for the determination of stress tensors for the Creighton 
Mine (Figure 3) that could be considered as seed for the Sudbury Basin stress tensor. The authors also discussed in detail the evolution of mining methods and support systems at Creighton Mine to manage high stress conditions.

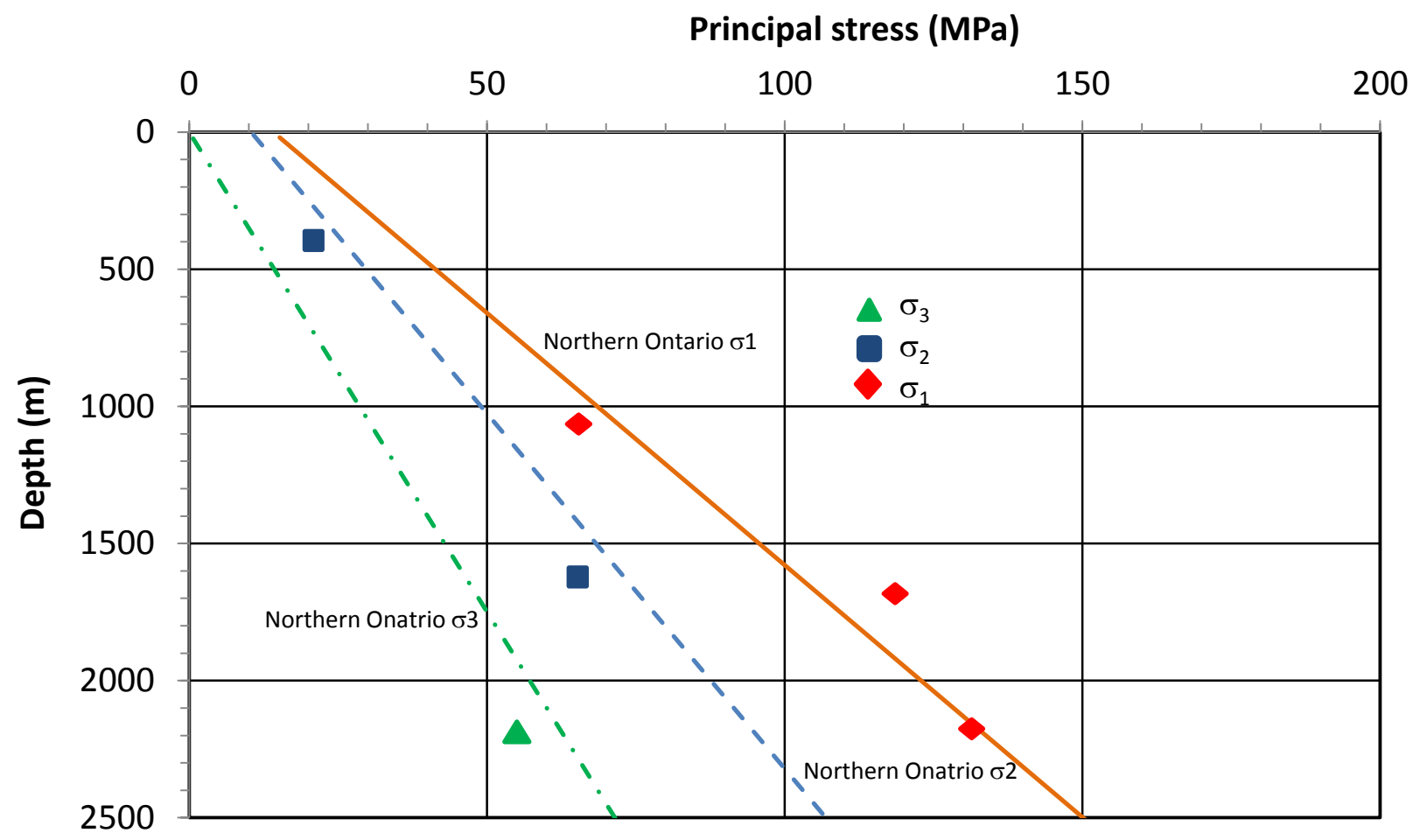

Figure 3 Creighton Mine stress tensor. Lines represent average northern Ontario principal stress gradients and solids are principal stress measurement data for Creighton Mine. Northern Ontario: $\sigma_{1}=14.45+0.0563 \mathrm{ZMa} / \mathrm{m} ; \sigma_{2}=10.35+$ $0.0423 \mathrm{z} \mathrm{MPa} / \mathrm{m} ; \sigma_{3}=0.029 \mathrm{z} \mathrm{MPa} / \mathrm{m}$ (Oliver et al. 1987)

\section{Development of a Sudbury Basin stress tensor}

Section 2 concluded that what is often quoted as the Sudbury Basin stress tensor cannot be traced and verified. The validity and reliability of this stress tensor could not be validated since the source database cannot be evaluated. There is also no evidence of it ever being updated.

Vale Sudbury mines cover a representative area of the Sudbury Basin. In over a century operations of the Vale mines in Sudbury, several in situ stress measurements have been conducted. From 1974 to date, there have been various in situ stress measurement campaigns to understand the stress regimes in which the various mines are located. The mines continue to update their stress measurements database as part of due diligence.

\subsection{Analysis of the Vale in situ stress measurements database}

A comprehensive analysis of the Vale in situ stress measurement database was undertaken as part of a FEL2 feasibility study (Suorineni 2012) in collaboration with Stantec Consulting Ltd. The goal of the study was to review the Vale Sudbury Basin in situ stress measurement database and develop appropriate far field stress tensors for input into numerical modelling stress analysis codes for the selection of mining methods and optimisation of stoping sequences.

\subsubsection{Approach}

A strategy was adopted with the view of identifying erratic measurements to obtain what can be described as a Sudbury Basin stress tensor by combining and analysing all the Vale Sudbury mines stress measurement data. Specific analysis were also conducted for the Creighton and Copper Cliff mines using 
their specific databases but the results are not included in this paper as the paper focus is on the Sudbury Basin stress tensor.

The procedure used was as follows:

- Review the Canadian Shield in situ stress measurement databases and stress tensors.

- Review the stress tensors currently used in modelling the various Vale Mines.

- Determine what conditions flag erratic stress measurements and eliminate such erratic measurements.

- Carry out statistical analysis to determine the magnitudes of the principal stresses from the filtered database.

- Use DIPS (Rocscience inc. 2012) to determine the mean orientations of the major far field principal stresses.

- Conduct basic modelling to compare the stress tensor developed with the current Sudbury Basin stress tensor.

Review of the Canadian Shield in situ stress tensor and current stress tensors used the various Vale mines provided logic for identifying erratic measurements in the Vale database. This process was supplemented with comments in the database. An example of this process is that the review and general experience in Canada and in the Sudbury Basin is that the minimum principal stress is approximately vertical with the major and minor principal stresses near horizontal. Hence, stress measurements that show significant deviations from this experience are considered erratic. Such errors may be due to measurements close to geologic structures or excavations, or possibly from instrumentation errors.

\subsubsection{Results}

The stress measurements database is plotted in Figure 4 showing the principal stress gradients. Figure 5 shows orientations of the principal stresses. Figure 4 shows that at depths greater than $1,500 \mathrm{~m}$ the data appear to deviate from the general trend while Figure 5 shows vertical stress orientations that are sub-horizontal.

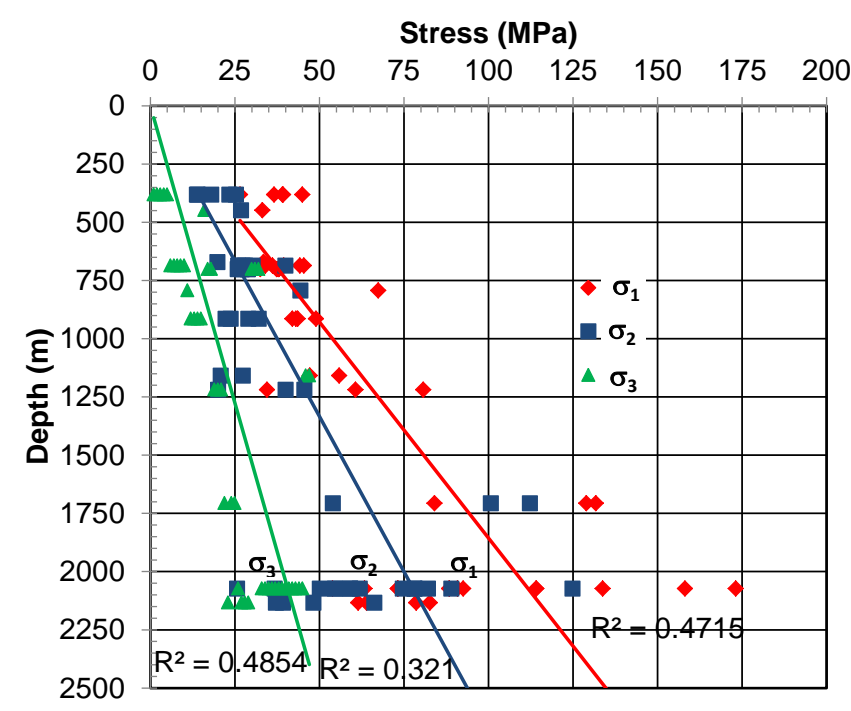

Figure 4 Principal stress gradients - unfiltered data 


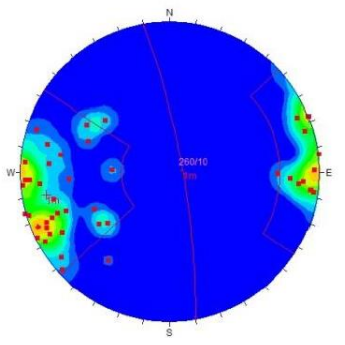

(a)

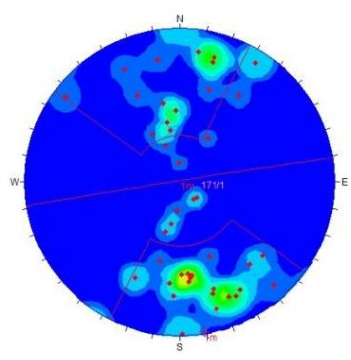

(b)

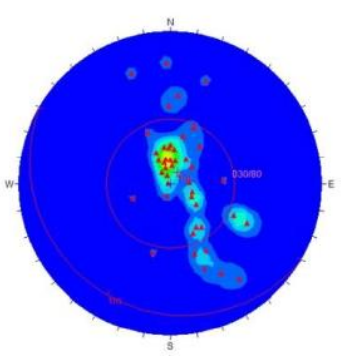

(c)

Figure 5 Principal stress orientations - unfiltered; (a) major principal stress $\left(\sigma_{1}\right)$; (b) intermediate principal stress $\left(\sigma_{2}\right)$; and (c) minimum principal stress $\left(\sigma_{3}\right)$

Based on the reviews, discussions and experiences on stresses in the Sudbury Basin and in the Canadian Shield the following conclusions were made and used as basis for eliminating erratic stress data:

- The minor principal stress in the basin must be sub vertical. Near horizontal minimum stresses are likely erratic.

- Measured minimum principal stresses must not differ by more than $10 \mathrm{MPa}$ from the theoretical values. This is within expected errors quoted by Grabinsky et al. (1997).

- Major $\left(\sigma_{1}\right)$ and intermediate $\left(\sigma_{2}\right)$ principal stresses in the Sudbury Basin and Canadian Shield are near horizontal and any subvertical $\sigma_{1}$ and $\sigma_{2}$ are likely erratic.

Note that an erratic $\sigma_{3}$ implies data for that stress measurement point is invalid (i.e. $\sigma_{1}$ and $\sigma_{2}$ should be ignored). Similarly, if $\sigma_{1}$ or $\sigma_{2}$ values or orientations are erratic results for those points are also removed.

Figures 6 and 7 show the resultant principal stress gradients and their orientations following data preprocessing. Figure 7 shows a significant increase in the coefficient of regression $\left(R^{2}\right)$ compared to what is given in Figure 4. Table 2 is a summary of the principal stresses and their orientations for the filtered data.

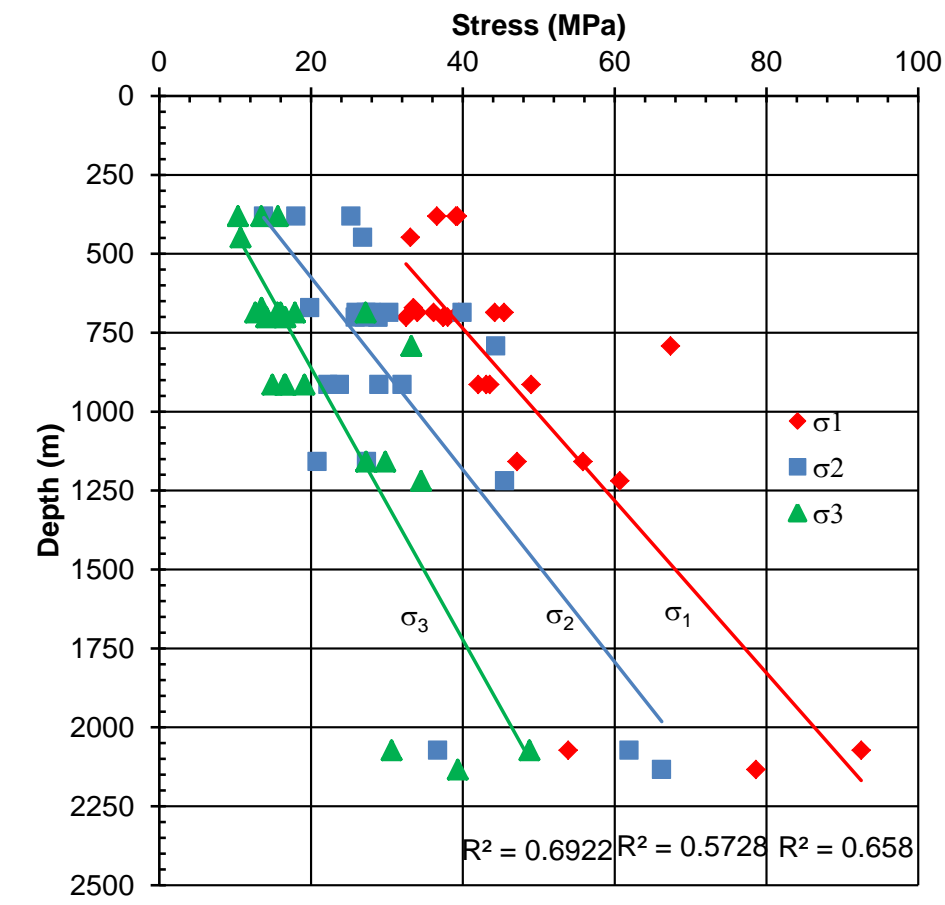

Figure 6 Principal stress gradients after filtering data 


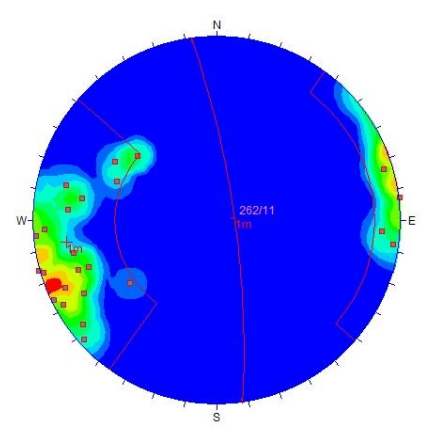

(a)

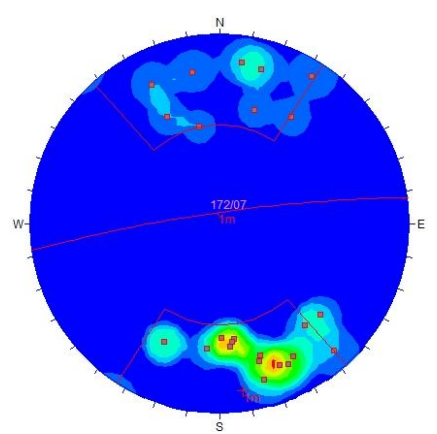

(b)

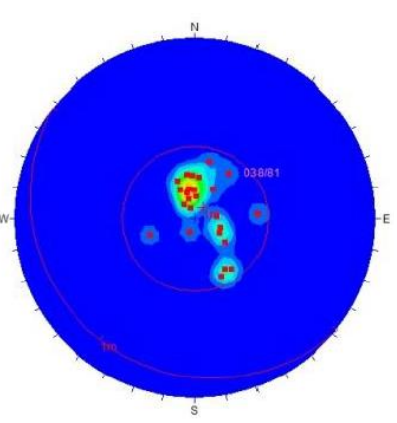

(c)

Figure 7 Principal stress orientations after data filtering; (a) major principal stress $\left(\sigma_{1}\right)$; (b) intermediate principal stress $\left(\sigma_{2}\right)$; and $(c)$ minimum principal stress $\left(\sigma_{3}\right)$

Table 2 Principal stresses and their orientations from filtered stress data

\begin{tabular}{ccc}
\hline Principal stress & Magnitude (MPa) & Orientation (dip/azimuth) $\left(^{\circ}\right)$ \\
\hline$\sigma_{1}$ & $13.027+0.0366 Z$ & $11 / 262$ \\
$\sigma_{2}$ & $1.114+0.0328 Z$ & $07 / 172$ \\
$\sigma_{3}$ & $0.0232 Z$ & $81 / 038$ \\
\hline
\end{tabular}

\section{$4 \quad$ Discussion of the results}

Figure 8 compares resultant stresses from the Vale Ltd. mines in situ stress measurements databases (Table 2) with the mystic Sudbury Basin stress tensor (Table 1).

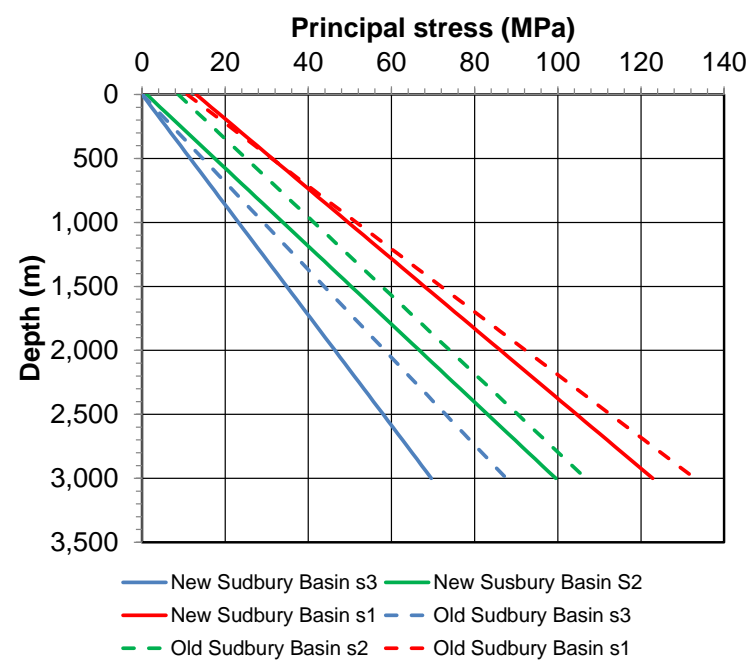

Figure 8 Comparison of the new and current Sudbury Basin stress tensors

Figure 8 clearly demonstrates the new Sudbury Basin stress tensor from the Vale database shows lower stresses at depth compared to the 'mysterious' Sudbury Basin stress tensor. In particular, the vertical stress is significantly less in the new stress tensor compared to the mysterious Basin stress. This is consistent with experiences reported by Morrison and Galbraith (1990) and Morrison (1993) at Copper Cliff North Mine. They noted that the confining stresses, i.e. the minor and intermediate principal stresses, at North Mine were anomalously very low, about $60 \%$ less than the regional stress model. This is supported by Phil Oliver's experience at Creighton too (Oliver, pers. comm.) when he made a strategic decision to equate the 
vertical stress to the intermediate principal stress in stress analysis. These observations are further supported in Suorineni (2012) for the Copper Cliff mines.

Phil Oliver worked for then Inco Ltd Sudbury Basin mines for several years until his retirement. Oliver (pers. comm., 2012) states that the average stress measurements results for the principal stress tensor at Creighton Mine, is near horizontal and oriented at an average strike of N65E and is consistent with the general strike of the footwall norite contact. This contradicts the true east-west orientation of the major principal stress in the mysterious Sudbury Basin stress tensor.

Further overcoring work at other Inco mines in the Sudbury Basin showed the major principle stress tensor orientation was close to that for Creighton Mine (Oliver, pers. comm.). The 'mystic' Sudbury Basin major principal stress orientation is horizontal and strike east-west. The new Sudbury Basin major principal stress is near horizontal and strike $\mathrm{N} 82^{\circ} \mathrm{E}$. Oliver further states that insofar as the intermediate and least stress magnitude equations are concerned, they were early formulations (Figure 3 ) that had been changed to a hydrostatic case.

\section{Comparison of the effects of the new and mystic Sudbury Basin stress tensors on excavation stability}

An elastic 3D model using Map3D (Wiles 2013) of a shaft (Figure 9(a)) at $1500 \mathrm{~m}$ depth is used to demonstrate the effect of the two stress tensors for comparison of their effect on excavation stability. All parameters in the model are the same except for the input stresses. The results are shown in Figure 9(b) and $\mathrm{c}$ for the mystic Sudbury Basin stress tensor and the new stress tensor respectively.

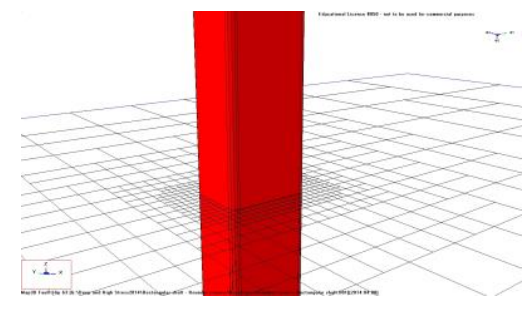

(a)

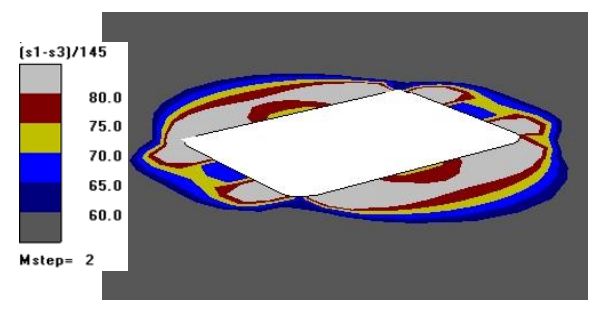

(b)

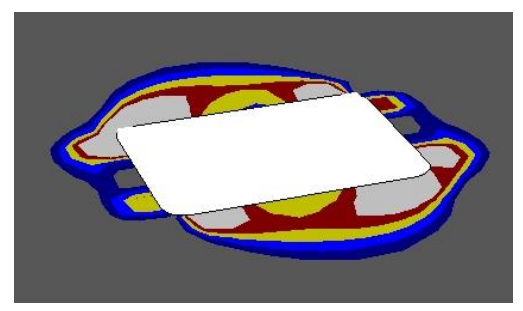

(c)

Figure 9 Comparison of the old and new Sudbury Basin stress tensors; (a) section of shaft with a grid at $1,500 \mathrm{~m}$; (b) old Sudbury Basin stress tensor; and (c) new Sudbury Basin stress tensor

Figure 9 is merely illustrative of the difference in impact of the old and new stress tensors. Underground observations are needed to validate these results. Based on the severity of the potential damage zone on the surface of the excavations the old stress tensor is more severe along the shaft walls parallel to its major axis than the new one. The potential damage zone is defined using the brittle Hoek-Brown damage initiation criterion (Martin 1993).

\section{Conclusions and recommendations}

Stress tensors are critical input into excavation design. This is more so in the Sudbury Basin where mines continue to go deeper and must deal with high stress conditions.

The Sudbury Basin stress tensor is historically important as it is used and referenced in many technical reports and publications. More importantly, it forms the basis for mining method selection and stope sequence optimisation at depth.

Recent studies prompted the validation of the Sudbury Basin stress tensor. The reliability of such a stress tensor depends on the quality and volume of the source data. Neither the source data nor the origin of the Sudbury Basin stress tensor could be traced. With continuing in situ stress measurement at the various 
Basin mines one would have expected an update of such an important regional stress tensor similar to the modifications of the individual mine stress tensors that are continuously modified with more experience and the continuing new stress measurement data.

Based on the diligent in situ stress measurements carried out in Vale Sudbury Basin mines that are placed all around the Basin a stress tensor is developed and presented that can be described as the Basin stress tensor. The new stress tensor is compared with what is currently described as the Sudbury Basin stress tensor. The results show that the new stress tensor is less in magnitude than the current Basin stress tensor with $\sigma_{1}$ oriented $\mathrm{N} 82^{\circ} \mathrm{E}$. These characteristics of the new Sudbury Basin stress tensor compare favourably with observations and experience in Vale Sudbury Basin Mines.

It is recommended that with the continuing stress measurements in the Basin the new stress tensor can be validated with the addition of new data and underground observations.

\section{Acknowledgement}

This study was undertaken in collaboration with Stantec Consulting Ltd. Special thanks goes to Jim Paynter for his moral support and guidance throughout the project. The support of Bill Dawson of Vale Canada Ltd. is acknowledged.

\section{References}

Arjang, B \& Herget, G 1997, 'In situ ground stresses in the Canadian hardrock mines: an update', International Journal Rock Mechanics and Mining Sciences, vol. 34, no. 3/4, pp. 1-16.

Canadian Mining Industry Research Organization 1995, Canadian Rockburst Handbook, Canadian Mining Industry Research Organization, Sudbury.

Clayton, C 2002, 'Managing geotechnical risk', IGT Seminar, Zurich, webinar.

Grabinsky, MW, Curran, JH \& Bawden, WF 1997, 'Interaction between stress, mine geometry and rock mass behaviour at a Canadian Shield mine', CIM Bulletin, vol. 90, no. 1013, pp. 45-51.

Henning, JG \& Suorineni, FT 2001, Numerical modelling of the 120 orebody mining sequence, Report submitted to Dunn Harding, INCO Ltd., Mines Technical Services.

Herget, G 1988, Stresses in rock, A.A. Balkema, Rotterdam.

Hoek, E 1994, 'The challenge of input data for rock engineering', Letter to the editor, ISRM News Journal, vol. 2, no. 2 pp. 23-24.

Malek, F, Suorineni, FT \& Larsen, J 2005, 'Orepass performance monitoring - North Mine 1600 OP case study', Proceedings of the Maintenance Engineering/Mine Operators Conference, Canadian Institute of Mining and Metallurgy, Westmount, on CD-ROM.

Malek, F, Suorineni, FT, \& Vasak, P 2009, 'Geomechanics Strategies for rockburst management at Vale Inco Creighton Mine', in M Diederichs \& G Grasselli (eds), Proceedings of the 3rd CANUS Rock Mechanics Symposium, Canadian Institute of Mining and Metallurgy, Westmount.

Malek, F, Trifu, C, Suorineni, FT, Espley, S \& Yao, M 2008, 'Management of high stress and seismicity at Vale Inco Creighton Mine', Proceedings of the 42nd US Rock Mechanics Symposium and 2nd US-Canada Rock Mechanics Symposium, American Rock Mechanics Association, Alexandria, pp. 1069-1076.

Maloney, SM, Kaiser, PK \& Vorauer, A 2006, 'A re-assessment of in situ stresses in the Canadian Shield', Proceedings of the 41st US Symposium on Rock mechanics: 50 Years of Rock Mechanics - landmarks and Future Challenges, American Rock Mechanics Association, Alexandria.

Martin, CD 1993, 'Strength of massive Lac du bonnet granite around underground openings, PhD thesis, University of Manitoba, Winnipeg.

Morrison, DM 1993, 'Seismicity in the Sudbury area mines', in PR Young (ed.), Proceedings of the 3rd International Symposium on Rockbursts and Seismicity in Mines, A.A. Balkema, Rotterdam, pp. 379-382.

Morrison, DM \& Galbraith, JE 1990, 'A case history of Inco's Cooper Cliff North Mine', Proceedings of the $31^{\text {st }}$ US Symposium on Rock Mechanics, A.A. Balkema, Rotterdam, pp. 51-58.

Morrison, RBK 1942, 'Report on the rockburst situation in Ontario mines', Canadian Institute of Mining and Metallurgy, vol. 45.

Natural Resources Canada 2014, Map of the Sudbury Structure, Natural Resources Canada, viewed 18 August 2014, http://www.nrcan.gc.ca

Oliver, PH, Wiles, T, MacDonald, P \& O'Donnell, D 1987, 'Rockburst Control Measures at Inco's Creighton Mine', Proceedings of the 6th Conference on Ground Control in Mining, University of West Virginia, West Virginia, pp. 79-90.

Rocscience inc. 2012, Dips: Graphical and Statistical Analysis of Orientation Data, Rocscience inc., Toronto, https://www.rocscience.com/products/1/Dips.

Suorineni, FT 2012, Copper Cliff Mine (CCM) Stress Tensor Development, reported submitted to Stantec Consulting Ltd.

Suorineni, FT \& Thibodeau, D 2013, 'Support selection for rapid drift development with drill and blast - Methodology and a case study', Rapid Drift Development Conference, International Mining, Sydney. 
Suorineni, FT, Kaiser, PK, Mgumbwa, JJ \& Thibodeau, D 2011, 'Mining of orebodies under shear loading - Part 1: Case histories', Transactions of the Institution of Mining and Metallurgy (Section A): Mining Technology, vol. 120, no. 3, pp. 137-147.

Vasak, P \& Suorineni, FT 2010, Mining-induced seismic periodicity and major rockburst occurrences, report submitted to D Thibodeau, Manager of Strategic Rock Mechanics, Canada Operations, Vale Ltd.

Vasak, P, Giovanni, G, Cai, M \& Suorineni, F 2006, Creighton Hazard Assessment Techniques Calibration, report submitted to Inco Creighton Mine, $48 \mathrm{pp}$.

Vasak, V, Suorineni, FT, \& Verma, A 2004, Identification of seismically active structures for hazard assessment at Creighton Mine, report prepared by MIRARCO Geomechanics Research Centre, Sudbury, for INCO Technology Centre.

Villaescusa, E, Machuca, L, Windsor, C, Simser, B \& Carlisle, S 2009, 'Stress measurements at great depth at Craig-Onaping Mines', Proceedings of the 6th International Conference \& Exhibition on Mass Mining: MassMin2012, Canadian Institute of Mining, Metallurgy and Petroleum, Westmount.

Wiles, T 2013, Map3D, Mine Modelling Pty Ltd, Mt Eliza, http://www.map3d.com 
